\title{
TENSIONES ENTRE DERECHO A LA INTIMIDAD Y LIBERTAD DE EXPRESIÓN. EL CASO ARGENTINO
}

\section{THE CONFLICT BETWEEN RIGHT TO INTIMACY AND FREEDOM OF SPEECH. THE ARGENTINEAN CASE}

\section{Mauro BENENTE}

RESUMEN: En el presente trabajo se intenta brindar un criterio para resolver determinadas tensiones entre el derecho a la intimidad y la libertad de expresión teniendo en cuenta el caso argentino y la insuficiencia de las pautas jurisprudenciales que los tribunales argentinos aplican. Para realizar la aproximación a tal criterio, se sostendrá que la protección a la libertad de expresión garantizada por el derecho positivo argentino posee un sustento filosófico más cercano al republicanismo que al liberalismo, con una concepción de la libertad de expresión como prerrequisito del sistema democrático. Finalmente, y una vez detallado el criterio que el autor propone, será el momento de ponerlo a prueba con un caso resonante resuelto por la Corte Suprema argentina.

Palabras clave: libertad de expresión, derecho a la intimidad, liberalismo, republicanismo, democracia.
ABSTRACT: The present work is intended to advance a criterion which could be used in order to solve some of the tensions between the right to privacy and the freedom of expression, considering the Argentinean case and the insufficiency of the judicial guidelines applied by the Argentinean courts. In order to perform the approach to this criterion, it will be affirmed that the freedom of expression secured by the Argentinean law is founded on a philosophical basis more connected with republicanism than with liberalism, which sees the freedom of expression as a prerequisite for the democratic system. Finally, and once having described the proposed criterion thoroughly, will come the time to put it to the test by means of a resounding case dealt with by the $\mathrm{Su}-$ preme Court.

Descriptors: Freedom of Expression, Right to Privacy, Liberalism, Republicanism, Democracy. 


\section{INTRODUCCIÓN}

Informaciones inexactas o que se inmiscuyan en esferas íntimas suelen generar tensión entre derechos, como son el de libertad de expresión y el derecho al honor o a la intimidad. Para el resolver casos en los que median informaciones inexactas, la jurisprudencia argentina ha erigido las doctrinas "Campillay" y de la "real malicia"; empero, ante informaciones que se entrometan en la intimidad de terceros, no parece haber un criterio consistente de resolución.

Mi misión será explorar el criterio que llamaré "aporte al debate político". Para hacerlo, indagaré sobre cuál es la tradición filosófica que subyace a la protección de la libertad de expresión en el ordenamiento jurídico argentino. Arribando a la conclusión de que es una posición cercana al republicanismo, sostendré que sólo están protegidas las informaciones que aporten al debate político, constituyéndose éste como un prerrequisito del sistema democrático.

Tras referirme a los alcances de la protección a la intimidad, intentaré resolver la tensión entre ésta y la libertad de expresión, para lo cual propondré el criterio del "aporte al debate político".

\section{LIBERTAD DE EXPRESIÓN. DOS TRADICIONES FILOSÓFICAS QUE LA SUSTENTAN}

La libertad de expresión, en tanto derecho, acepta una mirada liberal y una republicana que, según diré, no son del todo compatibles entre sí. Desde una perspectiva liberal, la libertad de expresión no es más que una consecuencia del principio de autonomía de la persona. Éste, que se configura como uno de los pilares de esta corriente filosófica, sostiene que

siendo valiosa la libre elección individual de planes de vida y la adopción de ideales de excelencia humana, el Estado (y los demás individuos) no debe interferir con esa elección o adopción; limitándose a diseñar instituciones que faciliten la persecución individual de esos planes de vida y la satisfacción de los ideales de virtud que cada uno sustente e impidiendo la interferencia mutua en el curso de tal persecución. ${ }^{1}$

1 Nino, Carlos Santiago, Ética y derechos humanos. Un ensayo de fundamentación, Buenos Aires, Paidós, 1984, p. 135. Cursiva en el original. 
Si se tiene por valiosa la libre elección de un plan de vida, por ejemplo ser pintor o periodista, el sujeto merece protección en la realización de su plan de vida, es decir, debe poder expresarse a través de sus cuadros o de un espacio en la radio, televisión o medio gráfico. El rol del Estado, de acuerdo con esta perspectiva, es de una abstención en cuanto al control del contenido de lo expresado, excepto que se dañe la autonomía de terceros. Lo importante, como vemos, no es más que la realización de la autonomía personal.

La concepción republicana asocia la libertad de expresión con el autogobierno o con el principio de no-dominación. El autogobierno encontraba sustento en el pensamiento de Rousseau, quien sostenía que somos libres cuando obedecemos leyes que consentimos y en las que tuvimos posibilidad de participar. ${ }^{2}$ Isaiah Berlin, sin ser un republicano, sintetizaba la idea de autogobierno con la de ser dueño de uno mismo, decidir por sí mismo sin que otros decidan por mí. ${ }^{3}$ El principio de no-dominación, por su lado, no hace hincapié en la idea de autogobierno, sino en la de reducción de la dominación por parte de otros agentes. ${ }^{4}$ Pettit, uno de los exponentes contemporáneos más reconocidos del republicanismo, sostiene que alguien tiene poder de dominación sobre otro cuando: "1) tiene capacidad para interferir 2) de un modo arbitrario 3) en determinadas

2 No es fácil resumir el pensamiento de Rousseau en pocas líneas. No obstante podemos decir que a diferencia de autores como Hobbes, Locke y Spinoza, el ginebrino concebía al Estado de naturaleza como un Estado venturoso, el mejor Estado del hombre. Sin embargo, a partir de la invención de la metalurgia y del surgimiento de la agricultura nacerá la propiedad privada, la desigualdad, la miseria, la rivalidad. Para Rousseau, el problema del Estado social está en cómo salvar, mantener y recuperar la libertad primitiva. Le preocupa "encontrar una forma de asociación que defienda y proteja con toda la fuerza común, la persona y los bienes de cada asociado [al pacto social], y por la cual cada uno, uniéndose a todos, obedezca tan sólo a sí mismo, y quede tan libre como antes", Rousseau, Jean-Jacques, El contrato social, Buenos Aires, Lozada, 2005, lib. 1, cap. VI, p. 56. Sin perjuicio de lo anterior, y a modo de introducción al pensamiento de Rousseau, recomiendo Prelot, Marcel y Lescuyer, Georges, Historia de las ideas politicas, Buenos Aires, La Ley, 1991, cap. XXVI; también Bobbio, Norberto y Bovero, Michelangelo, Sociedad y Estado en la filosofía política moderna, Buenos Aires, Fondo de Cultura Económica, 2000, primera parte.

3 Cfr. Berlin, Isaiah, "Dos conceptos de libertad", Cuatro ensayos sobre la libertad, Madrid, Alianza Universidad, 1988, pp. 201-205.

4 Cfr. Gargarella, Roberto, Las teorías de la justicia después de Rawls. Un breve manual de filosofía política, Barcelona, Paidós, 1999, pp. 161-166. 
elecciones que el otro pueda realizar", 5 por lo que "alguien disfruta de no-dominación, podemos decir, cuando vive entre personas que no satisfacen las tres condiciones". ${ }^{6}$

Ambos principios conciben a la democracia como el sistema de gobierno que mejor permite el autogobierno o que reduce la dominación de terceros. Esto es así, porque los sujetos eligen por quiénes serán gobernados - aunque para el caso se Rousseau la idea de representación sería contraria al autogobierno-, pueden participar del debate de toma de decisiones, tienen poder de crítica respecto de políticas consideradas inadecuadas, entre otros. En este orden de ideas, la protección de la libertad de expresión se configura como un requisito del debate político que debe preceder a la toma de decisiones y/o a la elección de candidatos, según la perspectiva de la democracia que se adopte y que más adelante veremos. ${ }^{7}$ De acuerdo con esta tradición filosófica, el Estado podría limitar ciertas expresiones que no contribuyan al debate político para hacer lugar a aquellas que sí lo harían.

Ahora bien, al tener en mente dos concepciones de la libertad de expresión podríamos pensar que, en tanto dos tradiciones filosóficas la respaldan, su configuración como derecho estaría sobrejustificada. El problema es que estas corrientes, según entiendo, no son del todo compatibles. En términos teóricos, y de acuerdo con Gargarella, el liberalismo concibe a los derechos como un límite a las decisiones mayoritarias, asociando a la libertad como "libertad frente a las voluntades democráticas", mientras que el republicanismo no pone límites a la voluntad mayoritaria, ya que la libertad existe en tanto sea miembro de una comunidad que controla su propio destino. ${ }^{8}$ En términos prácticos, y al decir de Nino,

5 Pettit, Philip, Republicanismo, una teoría sobre la libertad y el gobierno, Barcelona, Paidós, 1997, p. 78.

6 Ibidem, p. 96.

7 En Rousseau era clara la relación entre autogobierno y democracia, pero pensando en una democracia directa. No profundizaré la discusión acerca de cuál es el sistema que mejor satisface el autogobierno ni tampoco indagaré sobre cuál es la concepción de la democracia más cercana al autogobierno. En este sentido diré que el debate como prerrequisito del sistema democrático se orienta con la concepción republicana, pero no diré que la consagra.

8 Cfr. Gargarella, Roberto, op. cit., nota 4, p. 175. 
hay veces que estos dos objetivos, el de la promoción de la autonomía personal y el del enriquecimiento del debate público... entran en tensión y debe hacerse un balance cuidadoso entre ellos. Por ejemplo, el uso de medios de difusión para satisfacer preferencias individuales de distracción, esparcimiento y educación puede a veces restringir las posibilidades de emplearlos como foro del debate colectivo. ${ }^{9}$

Habiendo cierta incompatibilidad entre ambas concepciones, la tarea es determinar cuál es la adoptada por el derecho positivo argentino. Adelanto que tiene que ver con una idea de libertad de expresión como prerrequisito de la democracia, lo que nos orienta y aproxima a una tradición republicana. Si bien hay teorías de la democracia que parecen aproximarse al autogobierno más que otras, todas ellas (a todas las teorías de la democracia me refiero) se nutren, según veremos, del debate político.

\section{CONSTITUCión DE ARgentina y CONVENCiÓn AMERICANA SOBRE DERECHOS HUMANOS: LIBERTAD DE EXPRESIÓN, DEBATE Y DEMOCRACIA}

De las disposiciones del texto constitucional argentino no es fácil encontrar cuál concepción de la libertad de expresión subyace. El derecho de publicar sin censura previa consagrado por el artículo 14 y la prohibición al Congreso de "dictar leyes que restrinjan la libertad de imprenta o establezcan sobre ella la jurisdicción federal" consagrada por el artículo 32, no nos otorgan pautas del todo claras. No obstante, un primer indicio puede encontrarse en la Convención de la Provincia de Buenos Aires de 1860 que examinó la Constitución de 1853 y que propuso la incorporación del artículo $32 .{ }^{10}$ En aquélla, Vélez Sársfield sostuvo que la libertad de expresión

9 Nino, Carlos Santiago, Fundamentos de derecho constitucional, Buenos Aires, Astrea, 2002, p. 263.

10 Tras el Pacto de San José de Flores del 11de noviembre de 1859 y su Convenio Complementario del 6 de junio de 1860, el Estado de Buenos Aires convocó una Convención Provincial para revisar la Constitución de 1853, y en caso de proponerse reformas, el Congreso del Estado Argentino convocaría una Convención Constituyente ad hoc (Convención que fue convocada y reformó algunos puntos del texto constitucional). Aquella Convención Provincial estuvo integrada por Vélez Sársfield, Barros, Pasos, 
puede considerarse como una ampliación del sistema representativo o como su explicación de los derechos que quedan al pueblo, después que han elegido sus representantes al cuerpo legislativo. Cuando un pueblo elige a sus representantes no se esclaviza de ellos, no pierde el derecho de pensar o de hablar sobre sus actos; esto sería hacerlos irresponsables... Sólo la libre discusión por la prensa puede hacer formar el juicio sobre la administración o sobre los hechos políticos que deban influir en la suerte de un país. ${ }^{11}$

Si bien ideas como no-esclavitud del pueblo y libre discusión nos acercarían a tradiciones republicanas, las palabras de Vélez creo que se erigen como interesantes pero no determinantes a la hora de analizar al artículo 32: debemos concebirlas sólo como indicios. Esto es así porque toda interpretación originalista, es decir aquella que se pregunta por la voluntad del Constituyente, no logra demostrar la viabilidad de conocer cabalmente dicha voluntad - no sabemos si en realidad eran esas las ideas de Vélez o si sólo eran argumentos para que el artículo se introdujera a sabiendas de que se interpretaría de otro modo- y tampoco nos indica a qué convencional debemos prestarle atención — en este caso cité a Vélez y omití a Sarmiento y a Mitre, que entre otros, también integraron la Convención-. ${ }^{12}$

En esta búsqueda de indicios, diversos fallos de la Corte Suprema argentina parecen alinearse con las palabras de Vélez. En numerosos casos, el alto tribunal ha dicho que "entre las libertades que la Constitución Nacional consagra, la de prensa es una de las que poseen mayor entidad, al

Mitre, Sarmiento, Mármol, Domínguez y Cruz Obligado. Cfr. Vanossi, Jorge Reinaldo, Teoría constitucional, Buenos Aires, Depalma, 2000, t. I, pp. 372-385.

11 Sesión del 1o. de mayo de 1860, citado por Bertoni, Eduardo, Libertad de expresión en el Estado de derecho, Buenos Aires, Editores del Puerto, 2000, pp. 150 y 151. Reproducido parcialmente en "Costa Héctor R. c. Municipalidad de la Capital y otros", Fallos 310:508, cons. 13 del voto de la mayoría (Bacqué, Belluscio y Petracchi) y en "Ramos, Juan José c. LR3 Radio Belgrano y otros", Fallos 319:3428 cons. 9 del voto de la mayoría (Fayt, Belluscio, Petracchi, Boggiano y Bossert).

12 Para una mejor y más detallada exposición y crítica de la interpretación originalista véase Ely, John Hart, Democracia y desconfianza. Una teoría del control constitucional, Bogotá, Siglo del Hombre Editores, Universidad de los Andes, 1997, caps. I y II; Gargarella, Roberto, La justicia frente al gobierno. Sobre el carácter contramayoritario del Poder Judicial, Buenos Aires, Ariel, 1996, cap. 2 (en especial su apéndice). 
extremo de que sin el debido resguardo existiría tan sólo una democracia desmedrada o puramente nominal". ${ }^{13}$

Sin perjuicio de lo anterior, según creo, los indicios mencionados deben complementarse con las disposiciones de la Convención Americana sobre Derechos Humanos (CADH) y las interpretaciones realizadas por la Corte Interamericana de Derechos Humanos. ${ }^{14}$ De acuerdo con su artículo 13, la libertad de expresión comprende la "libertad de buscar, recibir y difundir informaciones e ideas de toda índole". Es decir que no sólo es importante que se exprese quien pretenda hacerlo, tal como lo pensaban los liberales; sino que también merece protección quien quiera recibir información, quien desee escuchar. La Corte Interamericana ha reconocido este doble régimen de protección ${ }^{15}$ y ha sostenido que "la libertad de expresión se inserta en el orden público primario y radical de la democracia, que no es concebible sin el debate libre y sin que la disidencia tenga pleno derecho de manifestarse". ${ }^{16}$ Creo que aquí está la concepción de la libertad de expresión que nuestro derecho positivo

13 “Abal, Edelmiro y otros c. Diario La Prensa” Fallos 248:291 cons. 25 del voto unánime (Villegas Basavilbaso, Aráoz de Lamadrid, Boffi Boggero, Oyhanarte, Aberastury, Colombres, Imaz). Repetido en "Abad, Manuel Eduardo y otros s/ calumnias e injurias" Fallos 315:632, cons. 5 de la disidencia de Cavagna Martínez, Barra y Fayt; "Servini de Cubría" Fallos 315:1943, cons. 6 del voto de la mayoría (Cavagna Martínez, Moliné O'Connor y Nazareno), cons. 10 del voto de Belluscio y cons. 23 de la disidencia de Petracchi; "Gesuladi, Dora M. c. Cooperativa Periodistas Independientes Ltda. y otros" Fallos 319:3085 cons. 4 del voto de Belluscio y López; "Díaz, Daniel c. Editorial La Razón”, Fallos 321:3170, cons. 6 del voto de Belluscio y Bossert; "Menem, Carlos s. C. Editorial Perfil S. A." Fallos 324:2895, cons. 6 del voto de la mayoría (Nazareno, Moliné O’Connor y López); "Baquero Lazcano, Silvia c. Editorial Río Negro S.A. y/u otros" Fallos 326:4136 cons. 16 del voto de la mayoría (Fayt, Belluscio, Petracchi, Boggiano y Maqueda); "Roviralta, Huberto c. Editorial Tres Puntos S. A." Fallos 327:789 cons. 4 de la disidencia de Fayt, entre muchos otros.

14 Recordemos que en 1994 la Constitución de Argentina fue profundamente reformada y entre los cambios introducidos se le otorgó jerarquía constitucional a numerosos tratados de derechos internacional de derechos humanos, entre ellos, la Convención Americana sobre Derechos Humanos.

15 Corte Interamericana de Derechos Humanos, La colegiación obligatoria de periodistas (artículos 13 y 29 de la Convención Americana sobre Derechos Humanos), Opinión Consultiva OC-5/85, del 13 de noviembre de 1985, Serie A, núm. 5, párrafos 32 y 33.

16 Ibidem, párrafo 69. En el mismo sentido se ha pronunciado la Comisión Interamericana de Derechos Humanos en el Informe 11/96, Caso 11.230, "Martorell, Francisco" (3 de mayo de 1996) punto V. 2. 
consagra: libertad de expresión para la libre formación de un debate de contenido político, sin el cual la democracia no existe. En este sentido, podría decirse que las expresiones merecen protección en cuanto contribuyan al debate político.

Si bien a continuación exploraré la relación entre debate y democracia, es importante retener que el sistema argentino protege las expresiones que contribuyan al debate político dado que, es a partir de esta idea, desde donde podemos encontrar algún criterio para resolver la tensión entre libertad de expresión y derecho a la intimidad.

\section{LIBERTAD DE EXPRESIÓN, DEBATE POLÍTICO Y DEMOCRACIA}

La idea de un debate libre y robusto como prerrequisito del sistema democrático está, en general, asociada con una concepción deliberativa de la democracia, pero, según creo, también debe asociarse con versiones que podrían considerarse más restrictivas.

\section{Debate politico y democracia deliberativa}

De acuerdo con la concepción deliberativa de la democracia, la toma de decisiones políticas debe hacerse luego de un amplio proceso de discusión colectiva, en el cual deben participar todos los posibles afectados. La idea central de esta teoría es que las decisiones políticas deben ser imparciales y una norma es imparcial cuando se adopta no para favorecer un grupo determinado de personas, sino porque se considera que su contenido es el más justo, tomando en consideración todos los intereses involucrados. ${ }^{17}$ Este tipo de teorías asigna valor a la libertad de expresión debido al debate que toda decisión política requiere. En este sentido, es menester que a todos aquellos que pretendan contribuir al debate político se les reconozca una protección jurídica, dejándose de lado posibles sanciones que, de existir, inhibirían el aporte.

De acuerdo con Carlos Nino, la democracia es el sistema más propicio para las decisiones imparciales, ya que permite el debate público,

17 Cfr. Gargarella, Roberto, "Crisis de representación y Constituciones contramayoritarias”, Isonomía. Revista de Teoría y Filosofía Política, México, núm. 4, 1995, pp. 91 y 92. También en "Representación plena, deliberación e imparcialidad", en Elster, Jon (comp.), La democracia deliberativa, Barcelona, Gedisa, 2001, pp. 324-326. 
siendo éste, el mejor método para acceder al conocimiento de la verdad moral, de la decisión más justa. Esto es así, porque permite que todos los potencialmente afectados por una decisión opinen y arguyan sobre la viabilidad de las medidas a tomar, lo que hace que los argumentos se perfeccionen, se contemplen todos los supuestos de hecho a tener en cuenta, se detecten los errores de razonamiento, entre otros. ${ }^{18}$

De acuerdo con esta perspectiva, es muy importante el debate tanto en términos cuantitativos como cualitativos: no sólo es trascendente que exista un gran debate, sino que todos y cada uno de los posibles afectados pueda expresarse. En este orden de ideas, Owen Fiss sostiene que para formar un debate vigoroso, es menester que el Estado lo regule, silenciando a los sectores que predominan, para darles voz a aquellos que permanecen callados o que nadie escucha. Para lograr su objetivo, vale aclarar, Fiss está pensando en políticas que tiendan a restringir las expresiones de sectores que predominan en los medios de comunicación y, a la vez, subsidiar a sectores minoritarios. ${ }^{19}$

\section{El debate politico en las teorias de Schumpeter y Dahl}

A diferencia del caso anterior, en el cual el debate político era tenido como un requisito para la toma de decisiones políticas, aquí cobra importancia, principalmente, al momento de la elección de candidatos.

Joseph Schumpeter propone su teoría como una alternativa a la teoría "clásica" de la democracia, a la que define "aquél sistema institucional de

18 Carlos Nino denomina su teoría "constructivismo epistemológico". Ésta, considerada intermedia entre las posturas de John Rawls y Jürgen Habermas, presenta una tesis ontológica y otra epistemológica de sobre la verdad moral. Su tesis ontológica afirma que la verdad moral se constituye por la satisfacción de presupuestos formales de una practica discursiva que tiene por objeto lograr cooperación y evitar conflictos; su tesis epistemológica sostiene que la discusión es el procedimiento más confiable para acceder a la verdad moral, ya que se detectan los errores del razonamiento y se escuchan todas las partes interesadas. Empero, esto no excluye que, de manera excepcional, mediante la reflexión individual (procedimiento menos confiable) se llegue a la mentada verdad. Cfr. Nino, Carlos Santiago, "Constructivismo epistemológico: entre Rawls y Habermas", Revista Doxa, Alicante, núm. 5, 1988, y La constitución de la democracia deliberativa, Barcelona, Gedisa, 1997, pp. 160-168.

19 Cfr. Fiss, Owen M., La ironía de la libertad de expresión, Barcelona, Gedisa, 1999, caps. 1 y 2 . 
gestación de las decisiones políticas que realiza el bien común". ${ }^{20}$ Para este autor, no existe tal bien común ya que es impensable que todos estén de acuerdo sobre un mismo tema, o que puedan ponerse de acuerdo a través de una discusión racional. Así, sostiene que

no hay tal bien común, unívocamente determinado, en el que todo el mundo pueda estar de acuerdo o pueda hacérsele estar de acuerdo en virtud de una argumentación racional. Esto no se debe primordialmente al hecho de que algunos puedan querer cosas distintas del bien común, sino al hecho mucho más fundamental de que, para los distintos individuos y grupos, el bien común ha de significar cosas diferentes. ${ }^{21}$

En este orden de ideas, afirma que son los líderes y no el pueblo los protagonistas de la vida política. El pueblo sólo se limita a concurrir a las urnas de manera periódica para decidir cuál de los líderes ha ganado la competencia. Aun autores muy críticos de esta teoría, como Carlos Nino, reconocen que la competencia entre líderes, y su posterior elección, requiere de un gran debate público. ${ }^{22}$

De la propuesta del Schumpeter surge la llamada teoría pluralista de la democracia, cuyo máximo exponente es Robert Dahl. ${ }^{23}$ Este autor no nos habla de democracia sino de poliarquía y se aparta del modelo de Schumpeter ya que no fija su atención en los líderes sino en los denominados grupos de interés, haciendo hincapié en la posibilidad de control

20 Schumpeter, Joseph A., Capitalismo, socialismo y democracia, Barcelona, Folio, 1984, p. 321.

21 Ibidem, p. 322.

22 Así, Carlos Nino sostuvo que "este tipo de competencia presupone libertad de expresión y libertad de prensa para que el pueblo pueda elegir a sus líderes", Nino, Carlos Santiago, op. cit., nota 19, p. 117.

23 Del tronco schumpeteriano nace también la teoría económica de la democracia, esgrimida, entre otros, por Anthony Dows y Brian Barry. A diferencia de Schumpeter, estos autores creen que el comportamiento del votante es racional, por lo que siempre elegirá en vistas a maximizar sus intereses. La explicación de esta teoría merece muchos párrafos más pero sólo quisiera dejar en claro que cuanto más debate exista es más probable que la elección sea la más racional. Cfr. Respuela, Sofía, "La democracia: una discusión en torno de sus significados", en Pinto, Julio, Introducción a la ciencia política, Buenos Aires, Eudeba, 2003, p. 296. 
que tienen los gobernados hacia sus gobernantes, fundamentalmente a través del voto. ${ }^{24}$

La tesis del control de los gobernados hacia los gobernantes se explica a través de una crítica a la noción de clásica de representación, y con el empleo de la noción del "voto retrospectivo" que Dahl y otros autores proponen. La idea según la cual los electores dan mensajes a sus representantes no tiene lugar; ya que dichos mensajes son confusos, el mandato democrático es un mito, ha dicho Dahl. ${ }^{25}$ En este orden de ideas aparece el llamado "voto retrospectivo": el electorado decide ex post si el representante satisfizo su interés, y en tal caso lo reelige; de lo contrario, puede elegir otro. En este orden de ideas, Sartori sostiene que lo importante de la teoría de la representación no es la semejanza entre representante y representando, sino que el primero rinda cuentas al segundo. En este sentido afirma que "la teoría electoral de la representación es, en efecto, la teoría de la representación responsable: su problema no es el de satisfacer el requisito de la semejanza, sino de asegurar la obligación de responder". ${ }^{26}$

Ahora bien, para un buen funcionamiento de esta rendición de cuentas, es menester una población informada respecto de la labor de los representantes, para que al momento de ir a las urnas, el elector cuente con todos los datos que podrían jugar a favor o en contra de una reelección. En pocas palabras, se requiere de un debate político robusto que permita al elector evaluar la conducta de todos y cada uno de los candidatos.

\section{Libertad de expresión y democracia mínima}

El nexo entre del derecho a la libertad de expresión y el debate político con el sistema democrático, ya sea que se lo conciba en su versión deli-

24 En una de sus últimas obras, Dahl afirmó que "la poliarquía es un régimen político que se distingue, en el plano más general, por dos amplias características: la ciudadanía es extendida a una proporción comparativamente alta de adultos, y entre los derechos de la ciudadanía se incluye el de oponerse a los altos funcionarios del gobierno y hacerlos abandonar sus cargos mediante el voto", Dahl, Robert A., La democracia y sus críticos, Barcelona, Paidós, 1993, p. 266.

25 Citado en Lujambio, Alonso, "Los problemas de la democracia según Gargarella", Isonomía. Revista de Teoría y Filosofía del Derecho, México, núm. 2, 1995, p. 117.

26 Sartori, Giovanni, Elementos de teoría politica, Buenos Aires, Alianza, 1992, p. 233. 
berativa o en una faz algo más restrictiva como la de Schumpeter y Dahl, tal vez pueda descifrarse si aun cuando retomamos definiciones mínimas de la democracia, el derecho a la libertad de expresión se encuentra presente o incluso se erige como presupuesto de ella.

Norberto Bobbio intentó proponer una definición mínima de la democracia, sugiriendo caracterizarla como "un conjunto de reglas (primarias o fundamentales) que establecen quién está autorizado para tomar las decisiones colectivas y bajo qué procedimientos" ${ }^{27}$ En este orden de ideas lo que caracterizaría a la democracia — en su definición mínimasería el instituto del sufragio extendido - cuya extensión daría el grado de democratización del sistema-, y la regla de la mayoría en la toma de decisiones. Asimismo, tanto aquellos que estén en posiciones de toma de decisiones cuanto quienes se encuentren en posición de elegir a sus representantes, deben tener posibilidades reales de seleccionar entre las diferentes opciones. Empero, para que

se realice esta condición es necesario que a quienes deciden les sean garantizados los llamados derechos de libertad de opinión, de expresión de la propia opinión, de reunión, de asociación, etcétera... Cualquiera que sea el fundamento filosófico de estos derechos, ellos son el supuesto necesario del correcto funcionamiento de los mismos mecanismos fundamentalmente democráticos que caracterizan un régimen democrático. Las normas constitucionales que atribuyen estos derechos no son propiamente reglas del juego: son reglas preliminares que permiten el desarrollo del juego. ${ }^{28}$

Años más tarde, Michelangelo Bovero — quien trabajara varios años junto con Bobbio - también intentó una definición mínima de la democracia, un núcleo duro, una gramática de la democracia. Esta gramática se constituiría con sustantivos, adjetivos y verbos. En lo que aquí nos interesa, focalizar sobre los verbos es lo que permite estipular una noción mínima del juego democrático. ${ }^{29} \mathrm{El}$ primero de los verbos es elegir, pero bajo el sistema democrático elegir significa:

27 Bobbio, Norberto, El futuro de la democracia, México, Fondo de Cultura Económica, 1996, p. 24.

28 Ibidem, p. 26.

29 Bovero, Michelangelo, Una gramática de la democracia. Contra el gobierno de los peores, Madrid, Trotta, 2002, p. 55. 
expresar un juicio (no improvisado) sobre el contenido de las decisiones ya tomadas en el periodo político precedente (entiendo por periodo político el intervalo entre dos elecciones) y sobre el contenido de las decisiones que deberán ser tomadas en el periodo sucesivo: significa, pues (a su manera), decidir cuáles deberán ser las decisiones políticas. ${ }^{30}$

El segundo de los verbos es representar y la representación es democrática cuando los elegidos no solamente son electos por la ciudadanía sino también en la medida en que logren reflejar las diversas tendencias del cuerpo social. Los restantes verbos son deliberar y decidir, siendo la decisión verdaderamente democrática "cuando en el momento deliberativo que la antecede han participado con las mismas oportunidades de valoración y de persuasión recíproca los representantes de todas las opiniones políticas". 31

Para un buen funcionamiento de los verbos que constituyen la noción mínima del juego democrático, es decir para un funcionamiento satisfactorio de elegir, representar, deliberar y decidir es menester que se garantice un amplio debate político, y así proteger la libertad de expresión. Para Bovero, la libertad de expresión, que equivale al derecho de disentir y criticar, no es una de las características de la democracia sino algo más que ello, es una de sus precondiciones. ${ }^{32}$

\section{DERECHO A LA INTIMIDAD}

Ciertas expresiones, referentes a cuestiones familiares por ejemplo, suelen entrar en tensión con el derecho a la intimidad que cada uno de nosotros posee, $y$, según entiendo, no tenemos criterios claros que nos permitan resolver esta problemática. Antes de pasar a los criterios, veamos cuál es la protección a la intimidad consagrada.

Es interesante pensar que suele asumirse con naturalidad que la Constitución argentina consagra el derecho a la intimidad cuando, en realidad, no parece haber ninguna norma clara al respecto. En este sentido, Nino

30 Ibidem, p. 61.

31 Ibidem, p. 65.

32 Ibidem, pp. 49 y 50. 
ha encontrado el derecho a la intimidad en el artículo $18,{ }^{33}$ la Corte Suprema argentina ha sostenido que se halla en el artículo $19,{ }^{34}$ a lo que se adhieren autores como Gelli ${ }^{35}$ y Ekmekdjian, ${ }^{36}$ y alguna jurisprudencia de la Cámara de Apelaciones lo ha descubierto en el artículo 33. ${ }^{37}$

No sólo resulta problemática la ubicación en el texto constitucional, sino que tampoco es muy claro cuál es el ámbito de protección ni cuáles son sus alcances. Nino sostiene que se trata de "una esfera de la persona que está exenta del conocimiento generalizado por parte de los demás". 38 Delimitando un poco más la situación, la Corte Suprema argentina se

33 En este sentido afirma que "(e)n la Constitución vigente de 1853-60 el derecho a la intimidad está principalmente presupuesto por el artículo 18, cuando establece que el domicilio es inviolable, como también la correspondencia epistolar y los papeles privados; y una ley determinará en qué casos y con qué justificativos podrá procederse a su allanamiento y ocupación”. Nino, Carlos Santiago, op. cit., nota 10, p. 333.

34 Cfr. "Ponzetti de Balbín, Indalia c. Editorial Atlántida S. A.", Fallos 306:1892 (1984), cons. 8 del voto de la mayoría (Carrió y Fayt), cons. 6 del voto de Caballero y Belluscio. También en "Servini de Cubría", Fallos 315:1961 (1992), cons. 17 del voto de Boggiano y 14 de Barra; "Gutheim, Federico c. Alemann, Juan", Fallos 316:703, cons. 8 del voto de la mayoría (Levene (h), Cavagna Martínez, Barra, Fayt, Belluscio, Petracchi, Nazareno y Boggiano); "Menem, Carlos S. c. Editorial Perfil S. A. y otros", Fallos 324:2895, cons. 5 y 12 del voto de la mayoría (Nazareno, Moliné O’Connor y López) y cons. 10 del voto de Vázquez; entre otros. Recordemos que el artículo 19 del texto constitucional argentino dispone que "las acciones privadas de los hombres que de ningún modo ofendan al orden y a la moral pública, ni perjudiquen a un tercero, están sólo reservadas a Dios y exentas de la autoridad de los magistrados. Ningún habitante de la nación será obligado a hacer lo que no manda la ley ni privado de lo que ella no prohíbe".

35 Cfr. Gelli, María Angélica, Constitución de la Nación Argentina comentada y concordada, Buenos Aires, La Ley, 2004, pp. 203-208.

36 Cfr. Ekmekdjian, Miguel Ángel, Tratado de derecho constitucional, Buenos Aires, Depalma, 1994, t. II, pp. 456-472.

37 Así la CNCiv. y Com. Fed., Sala 2 en "Servini de Cubría” (3/7/1992), E. D. 148464, cons. 14. Recordemos que el artículo 33 del texto constitucional argentino prescribe que "las declaraciones, derechos y garantías que enumera la Constitución, no serán entendidos como negación de otros derechos y garantías no enumerados; pero que nacen del principio de soberanía del pueblo y de la forma republicana de gobierno".

38 Nino, Carlos Santiago, op. cit., nota 10, p. 327. En un sentido similar, Bidart Campos habla de una "zona de reserva personal, propia de la autonomía del ser humano, dentro de la cual podemos excluir las intrusiones ajenas y el conocimiento generalizado por parte de los terceros", Bidart Campos, Germán, Tratado elemental de derecho constitucional argentino, Buenos Aires, Ediar, 1993, t. I, p. 370. 
refirió a "las acciones, hechos o datos que, teniendo en cuenta las formas de vida aceptadas por la comunidad están reservadas al propio individuo y cuyo conocimiento y divulgación por los extraños significa un peligro real potencial para la intimidad". 39

Atento a la ausencia de una norma constitucional clara y al desacuerdo de la doctrina, trabajaré con la Convención Americana de Derechos Humanos que, según entiendo, nos enseña el camino a seguir. Su artículo 11 inc. 2 dispone que "nadie puede ser objeto de injerencias arbitrarias o abusivas en su vida privada, en la de su familia, en su domicilio o en su correspondencia...". ${ }^{40}$ De acuerdo con esta disposición no está absolutamente vedada la intromisión en esferas íntimas, sino que lo que se prohíbe es aquella que sea abusiva o arbitraria. Refiriéndose al artículo citado - aunque no en casos en los cuales el derecho a la intimidad estuviera en conflicto con el derecho a la libertad de expresión-, la Corte Interamericana ha dicho que "(e)l artículo 11 de la Convención prohíbe toda injerencia arbitraria o abusiva en la vida privada de las personas, enunciando diversos ámbitos de la misma como la vida privada de sus familias, sus domicilios o sus correspondencias", ${ }^{41}$ para luego agregar que "el ámbito de la privacidad se caracteriza por quedar exento e inmune a las invasiones o agresiones abusivas o arbitrarias por parte de terceros o de la autoridad pública". ${ }^{42}$

39 "Ponzetti de Balbín, Indalia c. Editorial Atlántida S. A.”, Fallos 306:1892 (1984), cons. 8 del voto de la mayoría, repetido en "Gutheim, Federico c. Alemann, Juan", Fallos 316:703, cons. 8 del voto de la mayoría (Levene (h), Cavagna Martínez, Barra, Fayt, Belluscio, Petracchi, Nazareno y Boggiano); "Menem, Carlos S. c. Editorial Perfil S. A. y otros”, Fallos 324:2895, cons. 12 del voto de la mayoría (Nazareno, Moliné O’Connor y López), entre otros.

40 En sentido similar, la Declaración Americana de los Derechos y Deberes del Hombre habla de "ataques abusivos" (artículo 5o.), la Declaración Universal de Derechos Humanos de "injerencias arbitrarias" (artículo 12) y el Pacto Internacional de Derechos Civiles y Políticos de "injerencias arbitrarias o ilegales" (artículo 17.1). Por su lado, el artículo 1071 bis del Código Civil se refiere al "que arbitrariamente se entrometiere en la vida ajena... perturbando de cualquier modo su intimidad...".

41 Caso "Escher y otros c. Brasil". Excepciones preliminares, fondo, reparaciones y costas. Sentencia del 6 de julio de 2009, serie C, núm. 199, pfo. 113.

42 Ibidem. También en Caso "Escué Zapata vs. Colombia. Fondo, reparaciones y costas". Sentencia de 4 de julio de 2007, serie C, núm. 165, pfo. 95. 
La Corte Interamericana ha expresado que la resolución de las tensiones entre el derecho al honor y el ejercicio de la libertad de expresión, debe hacerse caso por caso. Así, el Tribunal ha argumentado que se

reconoce que tanto la libertad de expresión como el derecho a la honra, acogidos por la Convención, revisten suma importancia, por lo que ambos derechos deben ser tutelados y coexistir de manera armoniosa. La Corte estima, al ser necesaria la garantía del ejercicio de ambos derechos, que la solución del conflicto requiere el examen caso por caso, conforme a sus características y circunstancias. ${ }^{43}$

Incluso teniendo en cuenta que la resolución de los casos en los cuales el derecho a la intimidad $-\mathrm{o}$ el honor en palabras de la Corte Interamericana ${ }^{44}$ entra en tensión con el derecho a la libertad de expresión debe hacerse caso por caso, según entiendo, es menester tener un criterio, una pauta, para resolver cada una de estas circunstancias. Asimismo, y según creo, la aplicación de este criterio nos establecerá si la intromisión en esferas privadas ha sido o no abusiva.

\section{LA NECESIDAD DE CRITERIOS A LA HORA DE RESOLVER SITUACIONES TENSAS}

Hay ciertas informaciones que generan cierta tensión, informaciones que no resulta tan clara la conveniencia de darlas a conocer: me refiero a

43 Caso "Tristán Donoso c. Panamá". Excepción preliminar, fondo, reparaciones y costas. Sentencia del 27 de enero de 2009, serie C, núm. 193, pfo. 93. También en "Herrera Ulloa c. Costa Rica". Excepciones preliminares, fondo, reparaciones y costas. Sentencia de 2 de julio de 2004, serie C, núm. 107, pfo. 106.

44 No es mi intención analizar si el derecho a la intimidad o el derecho al honor son asimilables o si entre ellos es posible trazar diferencias. No obstante, en alguna sentencia de la Corte Interamericana pareciera que el tribunal los toma como sinónimos. Así, en "Kimel" se lee que "la Corte se ha pronunciado con firmeza y constancia - como dije supra pfo. 3-, y del respeto que merece el derecho a la intimidad, al buen nombre, al prestigio, también concebidos como derecho al honor, a la honra o a la dignidad - conceptos que deben analizarse al amparo de la cultura que los define y tutela-y que puede verse mellado por el ejercicio abusivo de la libertad de expresión. "Eduardo Kimel c. Argentina". Fondo, reparaciones y costas. Sentencia del 2 de mayo de 2008, serie C, núm. 177, pfo. 6 del voto concurrente del juez Sergio García Ramírez (las cursivas fueron agregadas). 
aquellas de las cuales no se tiene fehaciencia de su veracidad o que pueden llegar a inmiscuirse en esferas íntimas de terceros. Ante estas situaciones es menester que quien tenga la voluntad de aportar información al debate político, conozca si puede llegar ser responsable (civil o penalmente) por su proceder. ${ }^{45}$ En pocas palabras, debe existir algún criterio que permita saber cómo brindar este tipo de informaciones, hasta dónde puede informarse en determinados temas. Esta importancia no está dada sólo por la preservación de quien informa, sino también para que el debate político sea lo más robusto posible. Es muy posible que la ausencia de criterios genere, en quien pretenda informar, un temor a tener que responder por lo expresado, lo que trae como consecuencia que la información sea callada, que el debate se reduzca.

Para el caso de informaciones inexactas que generen daño al honor de terceros, se encuentran afianzadas las más que conocidas dentro de la jurisprudencia argentina, doctrinas "Campillay" y de la "real malicia". De acuerdo con la primera — que lleva el título del caso judicial en el cual se aplicó por primera vez el criterio resolutivo-, quedará exento de responsabilidad quien informe "atribuyendo directamente su contenido a la fuente pertinente, utilizando un tiempo verbal potencial o dejando en reserva la identidad de los implicados". ${ }^{46}$ Atento a la doctrina de la real malicia (actual malice), creada por la Corte de los Estados Unidos en el caso "New York Times vs. Sullivan" 47 y adoptada por la Corte Suprema

45 Me refiero sólo a responsabilidades ulteriores porque tanto la Constitución argentina como la $\mathrm{CADH}$, son enfáticas en cuanto a la prohibición de la censura previa (artículos 14 y 13 respectivamente).

46 “Campillay, Julio c. La razón y otros”, Fallos 308:789, cons. 7 del voto de la mayoría. Repetido con ciertos matices en "Costa Héctor R. c. Municipalidad de la Capital y otros", Fallos 310:508, cons. 9 del voto de la mayoría (Bacqué, Belluscio y Petracchi) y cons. 9 y 10 del voto de Caballero; "Abad Manuel Eduardo y otros s/ calumnias e injurias" Fallos 315: 632, cons. 6 del voto de la mayoría (Belluscio, Petracchi, Nazareno y Boggiano); “Triacca c. La Razón y Dyn”, Fallos 316:2416, cons. 9-12 del voto de la mayoría (Boggiano, Barra, Levene (h), Nazareno y Moliné O’Connor) y cons. 9-12 del voto de Fayt, Belluscio y Petracchi; "Díaz, Daniel c. Editorial La Razón”, Fallos 321:3170, cons. 12 del voto de la mayoría (Nazareno y Moliné O’Connor), entre otros.

47376 US 254 (1964). E1 29 de marzo de 1960 el diario New York Times publicó una solicitada titulada "Escuchad sus voces clamorosas", la cual detallaba denuncias y reclamos formulados por ciudadanos contra actos de discriminación racial ejecutados por la autoridad policial. Al concluir su texto figuraban los nombres de 64 personas y, a continuación, y debajo de una línea de palabras que decían "los que luchamos diariamente en el sur por 
argentina en diversos fallos, ${ }^{48}$ las expresiones inexactas o falsas referidas a funcionarios públicos respecto de temas de relevancia institucional no generan responsabilidad, salvo que se probare que el periodista hubiera conocido la falsedad de la noticia o hubiera actuado con despreocupación acerca de su verdad o falsedad.

\section{LIBERTAD DE EXPRESIÓN Y DERECHO A LA INTIMIDAD. EL APORTE AL DEBATE POLÍTICO COMO CRITERIO}

Las doctrinas "Campillay" y de "la real malicia" resuelven pleitos en los cuales la información es inexacta y se produce un daño en el honor de un tercero. Ahora bien, al momento de analizar una posible injerencia arbitraria en esferas íntimas, como pueden ser relaciones de familia, tales criterios no resultan satisfactorios. Pensemos por ejemplo, en una información verdadera, pero que se refiera a la frecuencia con la cual un funcionario público mantiene relaciones sexuales. En este caso hipotético, la

la dignidad y libertad apoyamos firmemente esta solicitada", aparecían los nombres de 20 personas (de las cuales 18 eran sacerdotes de diversas ciudades del sur de los Estados Unidos). La solicitada era atribuida al "Comité de Defensa de Martin Luther King y de la lucha por la libertad en el sur" y enunciaba los nombres de los miembros del comité. Algunos de los hechos descritos en la solicitada eran inexactos. En este contexto, el Comisionado de Montgomery inició una acción contra el diario. El Tribunal del Condado de Montgomery hizo lugar a la acción de difamación de Sullivan, condenando a cuatro de los autores de la solicitada y al diario New York Times al pago de 500,000 dólares en concepto de indemnización. El fallo fue confirmado por la Suprema Corte del Estado de Alabama y vía "certiorari" se accedió a la Corte Suprema. Del voto del justice William J. Brennan, que reflejó el criterio mayoritario de la Corte, surgió la doctrina de la "real malicia". Cfr. Badeni, Gregorio, "Doctrina de la real malicia", La Ley, 1997-B, 1181, y Bertoni, Eduardo, op. cit., nota 12, cap. 3.

48 "Vago c. Ediciones La Urraca", Fallos 314:1517, cons. 11-12 del voto de la mayoría (Fayt y Barra); "Abad Manuel Eduardo y otros s/ calumnias e injurias", Fallos 315: 632, cons. 6-7 del voto de Cavagna Martínez, Fayt y Barra; "Rodríguez”, Fallos 318:1114, cons. 8-12 de la disidencia de Fayt y Boggiano; "Morales Solá, Joaquín M.", Fallos 319:2741 (aquí creo que todos los jueces, de un modo más o menos explícito, han resuelto de acuerdo con esta doctrina); "Gesuladi, Dora M. c. Cooperativa Periodistas Independientes Ltda. y otros", Fallos 319:3085 cons. 7-12 del voto de Boggiano y cons. 16-22 del voto de Vázquez; "Ramos, Juan José c. LR3 Radio Belgrano y otros", Fallos 319:3428 cons. 10-13 del voto de la mayoría (Fayt, Belluscio, Petracchi, Boggiano y Bossert); “Patitó, José Ángel y otro c. Diario La Nación y otros", Fallos 331:1530, entre otros. 
aplicación de la real malicia eximiría de responsabilidad a quien informe algo que no parece del todo correcto ya que, a primera vista, podría configurarse como una injerencia arbitraria.

En este orden de ideas, pienso que para el análisis de la arbitrariedad en la injerencia de esferas íntimas, debemos desarrollar un criterio que permita la difusión de aquellas informaciones que siendo íntimas puedan contribuir al debate político, pero que limite aquellas que no lo hagan. El criterio que propongo es del "aporte al debate político". Una injerencia será arbitraria cuando la difusión del suceso no contribuya ni enriquezca el debate político. ${ }^{49}$ Varios son los argumentos que encuentro para sustentar este criterio:

1. En primer lugar, y según desarrollé, el derecho positivo argentino protege la libertad de expresión desde una concepción cercana al republicanismo, es decir en cuanto contribuya al debate político. En este orden de ideas, una información que contribuya al debate, no puede configurarse como una injerencia arbitraria de esferas íntimas. No niego que pueda inmiscuirse, de hecho, en esferas íntimas, sino que no habrá arbitrariedad, que es aquello que prohíbe la $\mathrm{CADH}$. Como contrapartida, es obvio que una información que no contribuya al debate, si se ha inmiscuido en esferas íntimas, podría catalogarse como arbitraria.

2. Incluso quienes afirmen que es la concepción liberal de la libertad de expresión la que subyace nuestro ordenamiento, podrán servirse del criterio del aporte al debate político. La tradición liberal, protege la autonomía de una persona mientras no restrinja la autonomía de otra. Ahora bien, si pensamos que cualquier injerencia en la intimidad de un tercero afecta su autonomía, los liberales deberán demostrar cuándo tal intromisión es arbitraria (recordemos que la

49 En sentido similar, el Tribunal Supremo Español ha dicho que "cuando la libertad de información se quiere ejercer sobre ámbitos que pueden afectar a otros bienes constitucionales, como son el honor y la intimidad, es preciso para que su proyección sea legítima, que lo informado resulte de interés público, pues sólo entonces puede exigirse de aquellos a quienes afecta o perturba el contenido de la información que, pese a ello, la soporten en aras, precisamente, del conocimiento general y difusión de hechos y situaciones que interesen a la comunidad; T. S. España, sala 1a. en lo Civil, 11 de septiembre de 1997, “D., Agustina A. y otro v. M. Jorge G. y otros”, Resolución núm. 777/1997, 3o. fundamento de derecho. 
$\mathrm{CADH}$, sólo protege de injerencias arbitrarias). Para esto último, podría erigirse el criterio del aporte al debate político.

3. Por último, el aporte al debate político es un criterio que permite a quien posee la noticia, decidir de manera satisfactoria acerca de su publicación. Anteriormente sostuve que la importancia de los criterios no tenía como único objeto la protección de quien informa, sino también la de evitar que el debate público se reduzca, situación que puede darse en caso de que, al no existir criterios claros de responsabilidad, el periodista decida callar. En este sentido, quien tenga una información con potencial daño a la intimidad de un tercero tendrá que analizar si su publicación contribuye al debate político: si contribuye, estará protegido; si no contribuye y calla, el debate es muy probable que no se hubiera reducido porque, en definitiva, parecía que la información no lo enriquecía.

\section{EL CRITERIO DEL APORTE AL DEBATE POLÍTICO PUESTO A PRUEBA: EL CASO "MENEM C. EDITORIAL PERFIL"50}

Del resonante fallo dictado en septiembre de de la Corte Suprema - y por lo resonante es que me interesa trabajarlo - se extraen de manera muy escueta los hechos del caso. Según se afirma, la revista Noticias difundió sin autorización una serie de notas periodísticas e imágenes fotográficas sobre una presunta paternidad extramatrimonial de Carlos Saúl Menem, en aquel momento presidente de la República, y el estado anímico de su ex cónyuge respecto de tal situación. ${ }^{51}$ Como bien dice la Corte argentina, en este caso no está en juego la veracidad de los hechos, sino que es menester determinar si su difusión es una intromisión arbitraria en esferas íntimas. ${ }^{52}$

50 Fallos 324:2895, sentencia del 25 de septiembre de 2001.

51 Cons. 16 del voto de la mayoría (Nazareno, Moliné O’Connor y López). Belluscio no hace referencia a los hechos, afirmando que se han tratado en las instancias anteriores (cons. 8). López tampoco se refiere a los hechos y ni siquiera aclara por qué no lo hace.

52 El máximo tribunal sostuvo que "el punto central a dilucidar, en consecuencia, es la tensión entre el derecho a la libre expresión o información... y ... el derecho de protección de una esfera de intimidad" (cons. 5 del voto de la mayoría y 4 del voto de Belluscio") que "resulta irrelevante en autos el debate en torno a la verdad o falsedad de la información difundida pues, si bien ello es de interés cuando el bien que se invoca como lesionado es 
Ante esta situación la Corte repite el holding del voto de la mayoría en el caso, también resonante, "Ponzetti de Balbín", según el cual "en el caso de personajes célebres, cuya vida tiene carácter público o de personajes populares, su actuación pública o privada puede divulgarse en lo que se relacione con la actividad que les confiere prestigio o notoriedad, y siempre que lo justifique el interés general". ${ }^{53}$ En este orden de ideas, en el caso de Menem, se resolvió que tales informaciones no estaban justificadas por el interés de la comunidad, ${ }^{54}$ por lo que debía condenarse a la editorial.

Según entiendo, la línea de argumentación hubiera sido diferente, si para la resolución del caso se hubiera utilizado el criterio que he propuesto. Para determinar si la información contribuía al debate político, en primer lugar se debería haber abordado con una gran profundidad los hechos del caso. Por el contrario, la Corte se limitó a afirmar que la publicación de cuestiones de familia no estaban justificadas. ${ }^{55}$ Entiendo que esto puede tener que ver con la aplicación de la doctrina de "Ponzetti de Balbín”, que considero bastante restrictiva. De acuerdo con ésta, la información debe: 1. Relacionase "con la actividad que les confiere prestigio o notoriedad", y 2. Estar justificada por el interés general. Es claro que cuestiones de familia no se relacionan con la actividad que le confiere prestigio al presidente de la nación y que así presentadas — simplemente como cuestiones de familia - tampoco son de interés general.

Si la Corte hubiera trabajado con el criterio del "aporte al debate político", debería haber indagado qué tipo de publicación familiar se había he-

el honor, no lo es cuando la lesión consiste en la invasión al ámbito reservado de la intimidad" (cons. 7 del voto de Belluscio y en igual sentido, cons. 4 del voto de Vázquez).

53 Cons. 13 del voto de la mayoría, repetido de "Ponzetti de Balbín, Indalia c. Editorial Atlántida S. A.”, Fallos 306:1892, cons. 9 del voto de la mayoría (Fayt y Carrió). Recordemos que en este caso se analizaba la responsabilidad civil de una editorial que había publicado fotos agonizantes de Carlos Balbín - político varias veces candidato a presidente de la nación- sin autorización de sus familiares.

54 Se dice textualmente: "Que, en autos, tanto la difusión de cuestiones familiares íntimas por medio de la palabra escrita como la publicación de imágenes fotográficas —en todo caso no autorizadas por el actor en el tiempo y en el contexto en que fueron usadas por el medio de prensa- sobre presuntos vínculos familiares y sobre el estado anímico de su ex cónyuge en relación a tales lazos, configura una intrusión en la zona de reserva del sujeto no justificada por intereses superiores de la comunidad". Cons. 16 del voto de la mayoría y cons. 10 del voto Belluscio.

55 Cons. 16 del voto de la mayoría y cons. 10 del voto Belluscio. 
cho. De acuerdo a lo que pude investigar, las publicaciones en discordia datan del 27 de febrero de 1994 y 5 de noviembre de 1995. La primera de ellas refiere a una presunta paternidad extramatrimonial del entonces presidente Menem, las circunstancias en que ella tuvo lugar, etcétera. ${ }^{56}$ Ahora bien, en la segunda publicación encuentro datos que podrían concebirse como enriquecedores del debate: ${ }^{57}$ consta una declaración de la madre del chico en cuestión, en la que afirma que sufrió un robo de joyas valuadas en 230,000 dólares estadounidenses que, según dijo, habían sido regaladas por Carlos Menem; además se informa sobre una casa que esta señora estaba construyendo, valuada en 350,000 dólares estadounidenses, percibiendo un sueldo de sólo 3,808 dólares mensuales.

Ante estos hechos, el criterio del aporte al debate político podría ver en la información de un supuesto hijo una prueba, un indicio, de que tales joyas y tal casa eran producto del dinero del entonces presidente. El criterio que propongo no niega que la referencia a un hijo extramatrimonial sea una injerencia en esferas íntimas, no obstante tal información debe ser contextualizada: si hay indicios que el presidente le otorga dinero a una señora, los indicios crecen si se presume que tal persona es la madre de un hijo suyo, algo que años más tarde judicialmente se terminó comprobando que era cierto. ${ }^{58}$

El gobierno del entonces presidente Menem fue sospechado, y continúa siendo investigado, por numerosos y diversos casos de corrupción. El mismísimo Carlos Menem estuvo procesado con prisión preventiva domiciliaria entre el 7 de junio y el 21 de noviembre de 2001 acusado por el delito de asociación ilícita e, incluso, algunos de sus funcionarios han llegado a ser condenados por enriquecimiento ilícito. ${ }^{59} \mathrm{La}$ ausencia del criterio del "aporte el debate político" impidió a los jueces de la Corte Suprema contemplar en la información publicada por la revista Noticias,

56 Revista Noticias del 27 de febrero de 1994, pp. 60-65.

57 Revista Noticias del 5 de noviembre de 1995.

58 Cfr. Diario Perfil del 5 de noviembre de 2006, pp. 62 y 63.

59 Fue condenada por enriquecimiento ilícito María Julia Alsogaray que durante la Presidencia de Menem fue la funcionaria que llevó a cabo la privatización de la empresa de teléfonos Entel y de la siderúrgica Somisa, y luego fue nombrada como secretaria de Medio Ambiente. Cfr. Cámara Nacional de Casación Penal, sala IV, "Alsogaray, María J.", sentencia del 9 de septiembre de 2005, La Ley, 2005-F, 140, y Corte Suprema de Justicia de la Nación, “Alsogaray, María Julia”, sentencia del 22 de diciembre de 2008, La Ley, 2009-A, 553. 
ciertos desajustes patrimoniales en la presunta madre de un presunto hijo del entonces presidente.

Si se hubiera atendido a lo anterior, podría haberse afirmado que el debate político se había visto fortalecido: al momento de analizar la conducta de gobierno del presidente y pensando en el merecimiento de una futura reelección, se hubiera podido examinar, por ejemplo, cuál fue el argumento según el cual desmintió tales regalos; en caso de no desmentir, uno podría preguntarme por qué no lo hizo, cómo había obtenido el dinero para comprar las joyas, etcétera.

\section{PALABRAS FINALES}

Espero no haber sido muy ambicioso. He intentado encontrar qué tradición filosófica subyace la protección constitucional de la libertad de expresión en el ordenamiento argentino, e intenté demostrar la relación entre aquel derecho, el debate político y la democracia. Todo ello con el claro objetivo de encontrar algún criterio que nos permita resolver la tensión entre libertad de expresión y derecho a la intimidad. Espero no haber sido concluyente; no era mi objetivo: sólo he intentado realizar mi aporte al debate.

\section{BIBLIOGRAFÍA}

BADENI, Gregorio, "Doctrina de la real malicia”, La Ley, Buenos Aires, 1997-B, núm. 1181.

_- "Las doctrinas Campillay y de la 'real malicia' en la jurisprudencia de la Corte Suprema de Justicia", La Ley, Buenos Aires, 2000-C, núm. 1244.

BERLIN, Isaiah, "Dos conceptos de libertad", Cuatro ensayos sobre la libertad, Madrid, Alianza Universidad, 1988.

BERTONI, Eduardo, Libertad de expresión en el Estado de derecho, Buenos Aires, Editores del Puerto, 2000.

BIDART CAMPOS, Germán, Tratado elemental de derecho constitucional argentino, Buenos Aires, Ediar, 1993, t. I.

BobBio, Norberto, El futuro de la democracia, México, Fondo de Cultura Económica, 1996. 
y Bovero, Michelangelo, Sociedad y Estado en la filosofía politica moderna, Buenos Aires, Fondo de Cultura Económica, 2000.

Bovero, Michelangelo, Una gramática de la democracia. Contra el gobierno de los peores, Madrid, Trotta, 2002.

DAHL, Robert A., La democracia y sus críticos, Barcelona, Paidós, 1993.

EKMEKDJIAN, Miguel Ángel, Tratado de derecho constitucional, Buenos Aires, Depalma, 1994, t. II.

ElY, John Hart; Democracia y desconfianza. Una teoría del control constitucional, Bogotá, Siglo del Hombre Editores, Universidad de los Andes, 1997.

Fiss, Owen M., La ironía de la libertad de expresión, Barcelona, Gedisa, 1999.

GARGARELlA, Roberto, "Crisis de representación y Constituciones contramayoritarias", Isonomía. Revista de Teoría y Filosofía Política, México, núm. 4, 1995.

— L La justicia frente al gobierno. Sobre el carácter contramayoritario del Poder Judicial, Buenos Aires, Ariel, 1996.

— Las teorías de la justicia después de Rawls. Un breve manual de filosofía política, Barcelona, Paidós, 1999.

, "Representación plena, deliberación e imparcialidad", en ELSTER, Jon (comp.), La democracia deliberativa, Barcelona, Gedisa, 2001.

Gelli, María Angélica, Constitución de la Nación Argentina comentada y concordada, Buenos Aires, La Ley, 2004.

LujAMBio, Alonso, "Los problemas de la democracia según Gargarella", Isonomía. Revista de Teoría y Filosofía del Derecho, México, núm. 2, 1995.

NinO, Carlos Santiago, Ética y derechos humanos. Un ensayo de fundamentación, Buenos Aires, Paidós, 1984.

- "Constructivismo epistemológico: entre Rawls y Habermas", Revista Doxa, Alicante, núm. 5, 1988.

— La Constitución de la democracia deliberativa, Barcelona, Gedisa, 1997. 2002.

PETIT, Philip, Republicanismo, una teoría sobre la libertad y el gobierno, Barcelona, Paidós, 1997. 
Prelot, Marcel y LeSCUYer, Georges, Historia de las ideas políticas, Buenos Aires, La Ley, 1991.

RESPUElA, Sofía, "La democracia: una discusión en torno de sus significados", en PINTO, Julio, Introducción a la ciencia política, Buenos Aires, Eudeba, 2003.

Rousseau, Jean-Jacques, El contrato social, Buenos Aires, Argentina, Lozada, 2005.

SARTORI, Giovanni, Elementos de teoría política, Buenos Aires, Alianza, 1992.

SCHuMPETER, Joseph A., Capitalismo, socialismo y democracia, Barcelona, Folio, 1984.

VAnossi, Jorge Reinaldo, Teoría constitucional, Buenos Aires, Depalma, 2000, t. I. 